\title{
Relationships Between Carl Rogers' Person-Centered Education and the Community of Inquiry Framework: A Preliminary Exploration
}

\author{
Karen Swan, Cheng-Chia (Brian) Chen, and Denise K. Bockmier-Sommers \\ University of Illinois, Springfield
}

\begin{abstract}
The research reported in this paper explored links between the work of Carl Rogers on personcentered education and the Community of Inquiry (CoI) framework, which posits a model of supports for social collaborative learning. Findings suggest significant links between the Rogerian constructs of level of regard and empathy and the CoI concept of teaching presence. The findings suggest avenues for future research and practical ways for enhancing teaching presence in online courses.
\end{abstract}

Keywords: Community of Inquiry framework, Carl Rogers, person-centered education, empathy, high regard, teaching presence

Swan, K., Chen, C.C., \& Bockmier-Sommers, D.K. (2020). Relationships between Carl Rogers' person-centered education and the community of inquiry framework: A preliminary exploration. Online Learning, 24(3), 4-18. https://doi.org/10.24059/olj.v24i3.2279

\section{Relationships Between Carl Rogers' Person-Centered Education and the Community of Inquiry Framework: A Preliminary Exploration}

Online programs in the human-service professions are becoming more prevalent, which can be observed by merely conducting a Google search for online counseling and human service programs. In fact, online classes are rapidly becoming necessary to attract greater numbers of students and to provide access to students who might not otherwise be able to attend college in the human service professions. However, students in the human service professions are unique in that they must be trained to develop therapeutic, relationship-building and active listening skills, which are challenging at best to develop in the online format.

Happily, the work of Carl Rogers (1969) crosses the boundaries between psychology and education and can be applied to facilitating online courses in the human services. Rogers (1969) identified three "core conditions" that support facilitative practice in both counseling and education: empathy, genuineness, and unconditional positive regard. He theorized that these three conditions were necessary for the creation of relationships that support and facilitate both therapeutic conversations and educational interactions. It seems likely that the three conditions 
might support not only learning in online human services courses but in online courses in general. Interestingly, what is probably the most prevalent model of learning processes in online environments, the Community of Inquiry (CoI) framework, similarly identifies three "presences" that support learning: teaching presence, social presence, and cognitive presence (Garrison, Anderson, \& Archer, 2000).

The research reported in this paper investigated connections between Rogers' conditions and the CoI framework's presences In particular, the research investigated correlations among the responses of 242 students taking online classes at a small, Midwestern university on two surveys: the Barrett-Lennard Relationship Inventory (BLRI, Barrett-Lennard, 2015) which quantifies student perceptions of how their instructors enact Rogers' conditions, and the CoI Survey (Arbaugh et al., 2008), which measures student perceptions of the three presences in online classes.

In the sections that follow, Rogers' person-centered approach to education and the BLRI created to measure it are described, as are the CoI framework and the CoI Survey. The methods used to explore relationships between student perceptions of these two approaches are summarized and their results presented and discussed. Finally, the limitations of this research, the conclusions that can be drawn from it, and its practical implications are reviewed.

\section{Carl Rogers' Person-Centered Learning}

Carl Rogers was a clinical and educational psychologist who is best known for his personcentered or non-directive therapy (Smith, 2004). An admirer of the work of John Dewey, Rogers likewise believed in the importance of opening up to and theorizing from experience. Linking such concepts to the insights born of his clinical experience, Rogers maintained that the client usually knows better how to proceed than the therapist and argued that three conditions were necessary to unlock the client's insight: empathy, genuineness, and unconditional positive regard. According to Tausch and Huls (2014), empathy is defined as “...the emotional and cognitive ability to feel the problems or distress of another person combined with the desire to help or to relieve his/her distress" (p. 136). Genuineness is consistent with being authentic and transparent. Unconditional positive regard refers to accepting others regardless of circumstances (Rogers, 1969). Indeed, even today, recent research on therapy outcomes has revealed that at least empathy and unconditional positive regard, and possibly congruence are critical components of effective psychotherapy (Kirschenbaum, \& Jourdan, 2005).

In the 1960s, Rogers became convinced that the relationship between a teacher and a student could be seen as similar to that between a therapist and a client (Rogers, 1969). He theorized that the three conditions were necessary for the creation of relationships that support and facilitate both therapeutic conversations and educational interactions. He further maintained that learning was facilitated when instructors employed empathy, genuineness, and unconditional positive regard (Rogers, Lyon, \& Tausch, 2013). Considerable research supports the efficacy of this approach (Cornelius-White, 2007), and there is some indication that it is useful in technologyenhanced teaching and learning (Motschnig-Pitrik, 2013).

Reese (2013) reported that collaboration, the freedom to create knowledge, and critical thinking skills increased students' engagement and participation in learning activities. With regard to the freedom to create knowledge, face-to-face and online learning environments share this potentiality. In light of higher education's movement toward the online format, the question arises, however, as to whether the three conditions can be used to enhance relationships between instructors and their students when instructors and students are separated in space and time. 
Bockmier-Sommers, Chen, and Martsch (2017) found the use of empathy to be significantly related to engagement in online classrooms. Engagement in any classroom is key to learning and having the complex conversations needed for difficult topics, such as racism, trauma, and homophobia.

Indeed, Martin and Bockmier-Sommers (in press) found preliminary support for the use of Rogers' three conditions to facilitate such difficult conversations. The authors contend that professors must view students as co-learners as opposed to viewing themselves as the sole experts, which is consistent with Rogers' theorizing that each individual possesses the abilities and skills they need to become engaged learners.

\section{The Barrett-Lennard Relationship Inventory}

The Barrett-Lennard Relationship Inventory (BLRI) was developed by Godfrey BarrettLennard in 1962 as a means for assessing Rogers' conditions for successful therapy. Indeed, after many years of testing and revision, the author's research confirms the reliability and validity of the BLRI and that scores on it can predict positive change in clients (Barrett-Lennard, 2015). In the education arena, a 40-item version of the BLRI has been used to assess the strength and quality of the student teacher-relationships. Some studies suggest links between scores on this version of the BLRI and students' affective and academic learning (Griffin, 1977/1978, Mason \& Blumberg, 1969, Smeltko, 1982/1983).

The educational version of the BLRI is a 40-item survey instrument which measures student-teacher relationships in terms of student perceptions of the Rogerian conditions in their teachers. In the survey, two of the conditions, empathy and genuineness, essentially correspond with the meanings given by Rogers (1969). Empathy is defined as "the extent to which one person is conscious of immediate and felt awareness of another" Barrett-Lennard, 2015, p. 20). Genuineness is the degree to which one person is "functionally integrated in the context of their relationships with others" (Barrett-Lennard, 2015, p. 21). The highly genuine individual is completely honest, direct, and sincere in what is conveyed, but does not feel a compulsion to either communicate or withhold their perceptions.

The two other Rogerian conditions measured on the BLRI, level of regard and unconditionality of regard represent a division of the concept of unconditional positive regard into two distinct concepts suggested by previous testing of the inventory. Level of regard refers to the affective aspect of one person's response to another including not online liking, appreciation, and affirmation, but also dislike, impatience, and rejection. These latter feelings, of course, negatively impact the relationship. Unconditionality is specifically the degree of constancy of regard felt by one person for another, ranging from consistency across situations to responses changing and conditioned by differing situations.

\section{The Community of Inquiry Framework}

The Community of Inquiry (CoI) framework (Garrison, Anderson, \& Archer, 2000) is a process model of learning in online and blended environments, where the social construction of knowledge is made nontrivial by the separation of course participants in time and space. It assumes that, especially in higher education, worthwhile educational experiences are embedded in communities of inquiry composed of teachers and students and that learning occurs within such communities through the interaction of three core elements: cognitive presence, social presence, and teaching presence (Figure 1). 


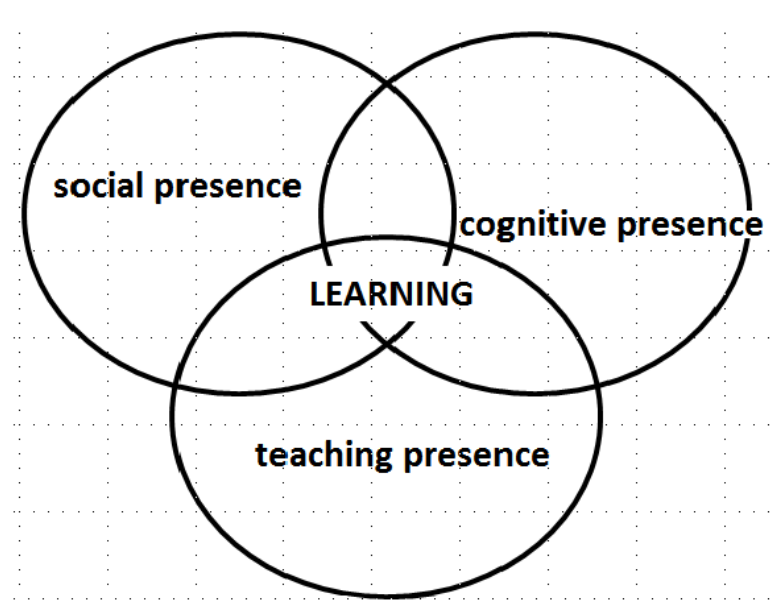

Figure 1. Community of Inquiry model (Garrison, Anderson, \& Archer, 2000).

In the CoI framework, social presence is defined as the ability of participants to project themselves socially and emotionally in an online class and correspondingly their ability to perceive other participants in that class as "real" (Swan \& Shih, 2005). Social presence is conceptualized as embodied by three types of behaviors-affective expression, the use of personal expressions of emotions, feelings, beliefs and values to project presence; group cohesion, interpersonal communication that builds and sustains a sense of community; and open communication, behaviors that encourage interaction and critical reflection by recognizing, complimenting and responding to others. Research has linked social presence to students' satisfaction and perceived and actual learning in online and blended classes (Richardson \& Swan, 2003; Picciano, 2002; Swan \& Shih, 2005).

Teaching presence includes course design and organization, the facilitation of learning, and direct instruction in online and blended courses (Garrison et al., 2000). Although these are all tasks that are generally undertaken by teachers, in the CoI framework teaching presence is not seen as attached to them but rather conceptualized as distributed across teachers, students, and materials. Researchers have documented strong correlations between learners' perceived and actual interactions with instructors and their perceived learning (Jiang \& Ting, 2000; Richardson \& Swan, 2003) and between teaching presence and student satisfaction, perceived learning, and the development of a sense of community in online courses (Shea et al., 2005). In fact, the body of evidence attesting to the critical importance of teaching presence for successful online learning continues to grow (Garrison, Cleveland-Innes \& Fung., 2010 Vaughan \& Garrison, 2006;), with the most recent research suggesting it is the key to developing online communities of inquiry (Kozan, 2016; Shea \& Bidjerano, 2009; Zhu et al., 2019).

Cognitive presence is defined as the extent to which learners are able to construct and confirm meaning in a virtual community of inquiry (Garrison, 2016). It is based on the Practical Inquiry Model (Garrison, Anderson, \& Archer, 2001) describes four phases in the pragmatic inquiry process. Practical inquiry, according to the model, begins with a triggering event, in the form of an issue, problem or dilemma that needs resolution, which elicits a natural shift to exploration, the search for relevant information that can provide insight into the challenge at hand. As ideas crystallize, there is a move into the third phase - integration - in which connections are made and there is a search for explanations. Finally, there is the selection and testing of the most viable solution and resolution around it. 


\section{The CoI Survey}

In 2008, researchers working with the CoI framework developed and validated a survey designed to measure student perceptions of social, teaching, and cognitive presence (Arbaugh, et al., 2008). The survey has been used to further explore the CoI framework and the interactive effects of all three presences (Garrison, Cleveland-Innes \& Fung, 2010; Shea \& Bidjerano, 2009) with some meaningful results. Boston and colleagues (2010) used the survey to explore relationships between the presences and student retention and found an important relationship between retention and social presence. Archibald (2010) found that teaching and social presence explained approximately $69 \%$ of the variance in cognitive presence, and that teaching and social presence continued to make significant contributions to the prediction of cognitive presence after controlling for self-directed learning readiness, prior online learning experience, and prior collaborative learning experience.

The CoI survey has also been used to inform the design and implementation of online courses. Ke (2010), for example, studied the interactions of teaching, cognitive, and social presence and their relationship to online instructional design, and identified design and teaching elements that were crucial prerequisites for successful online courses. Swan, Day, Bogle and Matthews (2014) used CoI scores to iteratively direct improvements in online graduated courses, resulting in significant increases in student outcomes.

\section{Methods}

The purpose of this research was to explore relationships between the conditions Carl Rogers identified as supporting person-centered learning and the CoI presences which many argue support the development of a community of inquiry.

\section{Subjects and Setting}

Subjects were recruited from the student population of small Midwest university. They were initially recruited through faculty members in each of the four colleges. A second round of recruitment was pursued through flyers distributed across campus and campus-wide email announcements. Two hundred and forty-eight students met the study requirement of having taken at least one online class. As part of the data analysis process, all variables were initially screened by checking regression assumptions, including linearity, homogeneity of variance and multicollinearity. Six subjects were identified as multivariate outliers through Mahalanobis distances $(p<.001$; Tabachnick \& Fidell, 2007) and removed from the dataset, reducing the sample size to 242 subjects.

Of the 242 eligible students who completed the online survey, 67\% $(n=163)$ students were on-campus students who had taken at least one online course, and 33\% $(n=79)$ were students who took all of their courses online. The majority of participants in this study were females $(70 \%)$. Subjects participated in the data collection online using their laptops or cell phones.

\section{Data Sources}

Two survey instruments were used to collect student perceptions of the Rogerian conditions and the CoI presences.

The Barrett-Lennard Relationship Inventory (BLRI; Barrett-Lennard, 2015) was used to measure student perceptions of Rogers' conditions for supporting person-centered learning. The 
BLRI contains a total of 40 items with which respondents are asked to indicate their agreement on a six-point bipolar scale ranging from -3 ("NO, I strongly feel that it is not true") to +3 ("YES, I strongly feel that it is true"). It returns scores on four subscales - one each for empathy, level of regard, unconditionality, and genuineness. To make the BLRI scores more similar to the COI scores, 3 points were added to scores on each BLRI item and then scores were averaged for each subscale.

Student perceptions of teaching, social, and cognitive presence were measured using the Community of Inquiry (CoI) Survey. The CoI Survey consists of a total of 34 Likert-type items (ranging along a five-point scale from "Strongly Disagree" to "Strongly Agree") that measure student perceptions of teaching, social, and cognitive presences in the online courses they take. The CoI Survey includes three subscales; the teaching presence subscale consists of 13 items; the social presence subscale consists of 9 items, and the cognitive presence consists of 12 items). CoI scores were averaged for each of the three subscales.

Both survey instruments measure student perceptions of teaching and learning processes in online courses. The dependent variables are scores on the three CoI presences and the four measurements in the BLRI model.

\section{Data Analyses}

Table 1 gives descriptive statistics for student perceptions of the three presences and the Rogerian conditions explored in this study. The mean total for each item is given in the first column and the standard deviation for that mean is in the second column. However, because the Community of Inquiry presences are measured by differing numbers of items, and the number of items measuring each of the Rogerian constructs is different still, we have divided the means by the number of items in each construct to calculate the average score for each.

Table 1

Mean Scores and Standard Deviations for Student Perceptions of CoI Presences and Rogerian Constructs $(\mathrm{n}=242)$

\begin{tabular}{lll} 
Variable/Construct & mean score & SD \\
\hline teaching presence & 4.02 & 0.67 \\
social presence & 3.76 & 0.70 \\
cognitive presence & 3.99 & 0.64 \\
level of regard & 4.42 & 1.00 \\
empathy & 4.27 & 0.95 \\
unconditionality & 3.50 & 0.77 \\
genuineness & 3.84 & 0.80
\end{tabular}

The average student perceptions were the highest for level of regard and empathy, followed by teaching and cognitive presence, genuineness, social presence, and finally unconditionality. 
Pearson's correlation coefficients were computed to explore the relationships among three CoI presences and four BLRI constructs. Table 2 reports the relationships among these seven theoretical concepts. The results of the correlational analyses indicated that all seven variables were positively correlated with one another, with variables from the same frameworks most strongly correlated with each other. Results also indicated meaningful correlations between all three presences and both level of regard and empathy, with the two Rogerian constructs accounting for between $19 \%$ and $26 \%$ of the variance in level of three presence scores. The relationship between teaching presence and empathy was the strongest.

Table 2

Pearson's Correlations among seven theoretical constructs from the CoI and BLRI surveys $(\mathrm{n}=$ 242)

\begin{tabular}{llllllll}
\hline Variable/Construct & $\mathbf{1}$ & $\mathbf{2}$ & $\mathbf{3}$ & $\mathbf{4}$ & $\mathbf{5}$ & $\mathbf{6}$ & $\mathbf{7}$ \\
\hline Teaching Presence (1) & - & & & & & & \\
Social Presence (2) & $.591^{* * *}$ & - & & & & & \\
Cognitive Presence (3) & $.671^{* * *}$ & $.649^{* * *}$ & - & & & & \\
Level of regard (4) & $.482^{* * *}$ & $.431^{* * *}$ & $.433^{* * *}$ & - & & & \\
Empathy (5) & $.505^{* * *}$ & $.455^{* * *}$ & $.471^{* * *}$ & $.887^{* * *}$ & - & & \\
Unconditionality (6) & $.253^{* * *}$ & $.246^{* * *}$ & $.224^{* * *}$ & $.521^{* * *}$ & $.505^{* * *}$ & - & \\
Genuineness (6) & $.332^{* * *}$ & $.310^{* * *}$ & $.287^{* * *}$ & $.740^{* * *}$ & $.717^{* * *}$ & $.425^{* * *}$ & - \\
\hline$*_{p<05, * * p<.01 *^{* * *}<<01}^{*}$ & & & & & & &
\end{tabular}

Because all the CoI and BLRI variables were correlated with each other, a series of partial correlations were then computed controlling for each of the variables in turn. The purpose of the partial correlation analyses was to further explore the strength of relationships between the CoI presences and the Rogerian constructs. In addition, regression analysis was used to investigate the effects of level or regard, empathy, unconditionality, and genuineness (independent variables) on teaching presence (dependent variable).

\section{Results}

Because all the CoI and Rogerian variables were correlated, a series of partial correlations were initiated, controlling for each of the variables in turn. Partial correlations measure the strength of association between two variables with the effects of another variable removed. The purpose of the partial correlation analyses was to further explore the strength of relationships between the CoI presences and the Rogerian constructs without the influence of possible confounding variable to identify the strongest links between CoI and BLRI variables. These results of these analyses are given in Tables 3 through Table 8. 
Table 3

Pearson's Partial Correlations among the study variables controlling for teaching presence $(\mathrm{n}=$ 242)

\begin{tabular}{lllllll}
\hline Variable/Construct & $\mathbf{1}$ & $\mathbf{2}$ & $\mathbf{3}$ & $\mathbf{4}$ & $\mathbf{5}$ & $\mathbf{6}$ \\
\hline Social Presence (1) & - & & & & & \\
Cognitive Presence (2) & $.421^{* * *}$ & - & & & \\
Level of regard (3) & $.207^{* * *}$ & $.169^{* *}$ & - & & \\
Empathy (4) & $.226^{* * *}$ & $.207^{* * *}$ & $.852^{* * *}$ & - & & \\
Unconditionality (5) & .123 & .076 & $.471^{* * *}$ & $.452^{* * *}$ & - & \\
Genuineness (6) & $.150^{*}$ & .093 & $.702^{* * *}$ & $.675^{* * *}$ & $.374^{* * *}$ & - \\
\hline
\end{tabular}

Controlling for teaching presence (Table 3) means that we are looking at the relationships among the study variables when we remove the confounding effects of teaching presence. Notice how much weaker the relationship between social and cognitive presence is when teaching presence is controlled for. Similarly, controlling for teaching presence yields considerably weaker relationships between social and cognitive presence and the BLRI variables. Notice that when teaching presence is controlled for, the relationships between social and cognitive presence and unconditionality and genuineness are no longer significant. At the same time, notice that the associations among the BLRI variables remain quite similar. This suggests that teaching presence probably is the most closely related of the CoI presences to the BLRI constructs.

The importance of teaching presence among the CoI/BLRI associations is supported by findings concerning controlling for social presence (Table 4) and cognitive presence (Table 5). Controlling for these two presences reduces the strength of the inter-CoI relationships in degrees similar to what happens when teaching presence is controlled for, but the CoI/BLRI relationships are not so drastically reduced. Indeed, the only relationships which are not significant in these correlations are those between cognitive presence and unconditionality and genuineness when social presence is controlled for.

Table 4

Pearson's Partial Correlations among the study variables controlling for social presence $(\mathrm{n}=$ 242)

\begin{tabular}{lllllll}
\hline Variable/Construct & $\mathbf{1}$ & $\mathbf{2}$ & $\mathbf{3}$ & $\mathbf{4}$ & $\mathbf{5}$ & $\mathbf{6}$ \\
\hline Teaching Presence (1) & - & & & & & \\
Cognitive Presence (2) & $.468^{* * *}$ & & & & & \\
Level of regard (3) & $.312^{* * *}$ & $.223^{* * *}$ & & & & \\
Empathy (4) & $.328^{* * *}$ & $.259^{* * *}$ & $.860^{* * *}$ & & & \\
Unconditionality (5) & $.138^{*}$ & .088 & $.475^{* * *}$ & $.456^{* * *}$ & & \\
Genuineness (6) & $.193^{* *}$ & .119 & $.707^{* * *}$ & $.680^{* * *}$ & $.379^{* * *}$ & - \\
\hline${ }^{*} p<.05, * * p<.01,{ }^{* * *} p<.001$ & & & & & &
\end{tabular}

${ }^{*} p<.05, * * p<.01, * * * p<.001$ 
Relationships Between Carl Rogers' Person-Centered Education and the Community of Inquiry Framework:

A Preliminary Exploration

Table 5

Pearson's Partial Correlations among the study variables controlling for cognitive presence $(\mathrm{n}=$ 242)

\begin{tabular}{lllllll}
\hline Variable/Construct & $\mathbf{1}$ & $\mathbf{2}$ & $\mathbf{3}$ & $\mathbf{4}$ & $\mathbf{5}$ & $\mathbf{6}$ \\
\hline Teaching Presence (1) & - & & & & & \\
Social Presence (2) & $.276^{* * *}$ & & & & & \\
Level of regard (3) & $.286^{* * *}$ & $.219^{* * *}$ & & & & \\
Empathy (4) & $.289^{* * *}$ & $.223^{* * *}$ & $.859^{* * *}$ & & & \\
Unconditionality (5) & $.142^{*}$ & $.136^{*}$ & $.483^{* * *}$ & $.465^{* * *}$ & & \\
Genuineness (6) & $.196^{* *}$ & $.170^{* *}$ & $.714^{* * *}$ & $.688^{* * *}$ & $.387^{* * *}$ & - \\
${ }^{*} p<.05, * * p<.01, * * * p<.001$ & & & & &
\end{tabular}

Just as correlations among BLRI variables remained quite similar when the COI presences were controlled for, so relationships among the CoI variables remained quite similar when the BLRI variables were controlled for. When the effect of level of regard (Table 6) and empathy (Table 7) are controlled for, however, those inter-CoI relationships are weaker than when unconditionality (Table 8) and genuineness (Table 9) are controlled for, and the former partial correlations result in few significant associations between the BLRI variables and all the study variables. These findings indicate that level of regard and empathy in particular are most closely related to the CoI presences.

Table 6

Pearson's Partial Correlations among the study variables controlling for level of regard $(\mathrm{n}=242)$

\begin{tabular}{lllllll}
\hline Variable/Construct & $\mathbf{1}$ & $\mathbf{2}$ & $\mathbf{3}$ & $\mathbf{4}$ & $\mathbf{5}$ & $\mathbf{6}$ \\
\hline 1. Teaching Presence (1) & - & & & & & \\
2. Social Presence (2) & $.485^{* * *}$ & & & & & \\
3. Cognitive Presence (3) & $.585^{* * *}$ & $.568^{* * *}$ & & & & \\
4. Empathy (4) & $.192^{* *}$ & $.176^{* *}$ & $.210^{* * *}$ & & & \\
5. Unconditionality (5) & .003 & .028 & -.001 & .109 & & \\
6. Genuineness (6) & -.042 & -.014 & -.055 & $.193^{* *}$ & .069 & - \\
\hline
\end{tabular}

${ }^{*} p<.05,{ }^{* *} p<.01,{ }^{* * *} p<.001$ 
Relationships Between Carl Rogers' Person-Centered Education and the Community of Inquiry Framework:

A Preliminary Exploration

Table 7

Pearson's Partial Correlations among the study variables controlling for empathy $(\mathrm{n}=242)$

\begin{tabular}{lllllll}
\hline Variable/Construct & $\mathbf{1}$ & $\mathbf{2}$ & $\mathbf{3}$ & $\mathbf{4}$ & $\mathbf{5}$ & $\mathbf{6}$ \\
\hline Teaching Presence (1) & - & & & & & \\
Social Presence (2) & $.470^{* * *}$ & & & & & \\
Cognitive Presence (3) & $.569^{* * *}$ & $.553^{* * *}$ & & & & \\
Level of regard (4) & .084 & .065 & .036 & & & \\
Unconditionality (5) & -.002 & .021 & -.018 & $.183^{* *}$ & & \\
Genuineness (6) & -.050 & -.026 & -.082 & $.324^{* * *}$ & .105 & - \\
${ }^{*} p<.05, * * p<.01, * * * p<.001$ & & & & &
\end{tabular}

Table 8

Pearson's Partial Correlations among the study variables controlling for unconditionality $(\mathrm{n}=$ 242)

\begin{tabular}{cllllll}
\hline Variable/Construct & $\mathbf{1}$ & $\mathbf{2}$ & $\mathbf{3}$ & $\mathbf{4}$ & $\mathbf{5}$ & $\mathbf{6}$ \\
\hline Teaching Presence & - & & & & & \\
Social Presence & $.564^{* * *}$ & & & & & \\
Cognitive Presence & $.651^{* * *}$ & $.628^{* * *}$ & & & & \\
Level of regard & $.423^{* * *}$ & $.366^{* * *}$ & $.380^{* * *}$ & & & \\
Empathy & $.451^{* * *}$ & $.396^{* * *}$ & $.425^{* * *}$ & $.847^{* * *}$ & & \\
Genuineness & $.256^{* * *}$ & $.234^{* * *}$ & $.218^{* * *}$ & $.672^{* * *}$ & $.643^{* * *}$ & - \\
\hline
\end{tabular}

${ }^{*} p<.05,{ }^{* *} p<.01,{ }^{* * *} p<.001$

Table 9

Pearson's Partial Correlations among the study variables controlling for genuineness $(\mathrm{n}=242)$

\begin{tabular}{lllllll}
\hline Variable/Construct & $\mathbf{1}$ & $\mathbf{2}$ & $\mathbf{3}$ & $\mathbf{4}$ & $\mathbf{5}$ & $\mathbf{6}$ \\
\hline Teaching Presence & - & & & & & \\
Social Presence & $.544^{* * *}$ & & & & & \\
Cognitive Presence & $.637^{* * *}$ & $.614^{* * *}$ & & & & \\
Level of regard & $.372^{* * *}$ & $.315^{* * *}$ & $.342^{* * *}$ & & & \\
Empathy & $.406^{* * *}$ & $.352^{* * *}$ & $.397^{* * *}$ & $.761^{* * *}$ & & \\
Unconditionality & $.132^{*}$ & $.133^{*}$ & .118 & $.339^{* * *}$ & $.317^{* * *}$ & - \\
\hline$*_{p}<.05, * * p<.01, * * * p<.001$ & & & & &
\end{tabular}


To test these initial findings, multiple regression analysis was conducted to assess the potential influence of Rogerian person-centered concepts on teaching presence in the CoI model. Prior to the analysis, linearity, normality, homoscedasticity, and multicollinearity assumptions were checked and all those assumptions were found to meet for analysis. As multicollinearity indicatives tolerance values were above 0.1 (0.185 to 0.718$)$ and variance inflation factors (VIF) were greater than 1 (Field, 2009).

The resulting multiple regression model can be expressed as

$$
\mathrm{TP}=0.145(\mathrm{LoR})+0.280(\mathrm{Emp})-0.012(\mathrm{UnCon})-0.089(\mathrm{Gen})+2.566 \text {. }
$$

Where $\mathrm{TP}=$ teaching presence, $\mathrm{LoR}=$ level of regard, $\mathrm{Emp}=$ Empathy, $\mathrm{UnCon}=$ unconditionality, and $\mathrm{Gen}=$ genuineness.

The prediction model was statistically significant, $\left(F_{(4,237)}=21.407, p<.001\right)$ and accounted for approximately $27 \%$ of the variance in teaching presence (R-squared $=.265$, adjusted $\mathrm{R}$-squared $=.253$ ). Additionally, we found that the estimated power to predict multiple R-squared is 1.000 and the effect size was .361. Moreover, the standardized coefficients for level of regard, empathy, unconditionality, and genuineness were $0.215,0.398,-0.012$, and -0.089 , respectively. These coefficients are standardized regression coefficients, which allows the researchers to compare the different degrees of Rogerian constructs' impact on teaching presence. Empathy, as indexed by its standardized beta value of .398, was shown to have the strongest relationship to teaching presence, followed by level of regard. In addition, the regression results suggest that unconditionality and genuineness are not associated with teaching presence. The results of the partial correlation controlling for teaching presence (Table 3), moreover, suggests that these latter two are not related to social or cognitive presence.

\section{Limitations}

The results of this research are limited by the sampling methodology employed. First, subjects were all drawn from a small Midwestern university whose students are mostly drawn from the state in which it is located. Two-thirds of the subjects were on-campus students taking at least one online class, and $70 \%$ were female, neither of which mirrors characteristics of the university population, let alone university students in general. Moreover, subjects were those who responded to voluntary recruitment and so may have other characteristics not common to the general population. In addition, the research results are limited by the survey instruments themselves used which are self-report. As the CoI and Rogerian concepts being investigated involve individual perception, self-reporting might be the only way to get at them, still the survey items might in some way limit the outcome. In sum, findings may be in some way suspect and may not be generalizable to a larger population.

\section{Conclusions}

The research reported herein was preliminary in nature. It was designed to explore possible connections between the Community of Inquiry presences and Rogerian constructs as measured by the CoI survey and the BLRI instrument. Thus, despite limitations, the results are intriguing. Findings indicate significant connections between level of regard and empathy and the CoI presences, teaching presence in particular. Indeed, taken together the two constructs accounted for $27 \%$ of the variance of teaching presence in the perceptions of the students in the study. 
These findings suggest avenues for future research and practical ways for enhancing teaching presence in online courses. They seem to indicate that online instructors could enhance teaching presence in their courses by working to project empathy and high levels of regard for their students. Future research should explore the effects of addressing instructor empathy and regard for students on student perceptions of teaching presence and on student outcomes. It also might be useful to look at connections between these findings and research on instructor social presence (Lowenthal, 2016; Richardson et al., 2015; Richardson \& Lowenthal, 2017). Finally, as we have good evidence linking teaching presence to students' satisfaction and learning (Shea, Li, Swan, \& Pickett, 2005), online instructors might focus on empathy in particular to enhance student success. 


\section{References}

Arbaugh, J. B., Cleveland-Innes, M., Diaz, S., Garrison, D. R., Ice, P., Richardson, J. C., Shea, P., \& Swan, K. (2008). Developing a community of inquiry instrument: Testing a measure of the Community of Inquiry framework using a multi-institutional sample. The Internet and Higher Education, 11(3-4), 133-136.

Archibald, D. (2010). Fostering the development of cognitive presence: Initial findings using the Community of Inquiry survey instrument. Internet and Higher Education, 13(1-2), 73-74.

Barrett-Lennard, G. T. (2015). The relationship inventory: A complete resource and guide. John Wiley \& Sons.

Bockmier-Sommers, D., Chen, C. C., \& Martsch, M. (2017). Student perception of teacher empathy, high regard and genuineness and the impact on student engagement. e-Mentor, $3(70), 66-72$

Cornelius-White, J. (2007). Learner-centered teacher-student relationships are effective: A metaanalysis. Review of Educational Research. 77(1), 113-143.

Field, A. (2009). Discovering statistics using IBM SPSS statistics (3rd ed.). Sage.

Garrison, D. R. (2016). E-Learning in the $21^{\text {st }}$ century: A Community of Inquiry framework for research and practice (3rd ed.). Routledge.

Garrison, D. R., Anderson, T., \& Archer, W. (2000). Critical inquiry in a text-based environment: Computer conferencing in higher education. The Internet and Higher Education, 2, 87-105.

Garrison, D. R., Anderson, T., \& Archer, W. (2001). Critical thinking, cognitive presence and computer conferencing in distance education. American Journal of Distance Education, 15(1), 7-23.

Garrison, D. R., Cleveland-Innes, M., \& Fung, T. (2010). Exploring causal relationships among cognitive, social and teaching presence: Student perceptions of the Community of Inquiry framework. The Internet and Higher Education, 13(1-2), 31-36.

Griffin, E. J. (1977/1978). A study of effects of a curriculum-centered college reading course and an affectively oriented curriculum focused course on reading achievement and attitude toward reading [Doctoral dissertation, University of Florida]. Dissertation Abstracts International, 38-A, 6429. http://archive.org/stream/effectsofcurricu00miln/effectsofcurricu00miln_djvu.txt

Jiang, M., \& Ting, E. (2000). A study of factors influencing students' perceived learning in a web-based course environment. International Journal of Educational Telecommunications, 6(4), 317-338.

Kirschenbaum, H., \& Jourdan, A. (2005). The current status of Carl Rogers and the personcentered approach. Psychotherapy: Theory, Research, Practice, Training, 42(1), 37-51.

Ke, F. (2010). Examining online teaching, cognitive, and social presence for adult students. Computers \& Education, 55(2), 808-820. 
Kozan, K. (2016). A comparative structural equation modeling investigation of the relationships among teaching, cognitive and social presence. Online Learning, 20(3), 210-227.

Lowenthal, P. R. (2016). A mixed methods examination of instructor social presence in accelerated online courses. In L. Kyei-Blankson, J. Blankson, E. Ntuli, \& C. Agyeman (Eds.), Handbook of research on strategic management of interaction, presence, and participation in online courses (pp. 147-159). IGI Global.

Mason, J., \& Blumberg, A. (1969). Perceived educational value of the classroom and teacherpupil interpersonal relationships. Journal of Secondary Education, 44, 135-139.

Motschnig-Pitrik, R. (2013). Characteristics and effects of person-centered technology enhanced learning. In J. H. Cornelius-White, R. Motschnig-Pitrik., \& M. Lux (Eds)., Interdisciplinary applications of the person-centered approach (pp. 125-131). Springer Science \& Business Media.

Picciano, A. G. (2002). Beyond student perceptions: Issues of interaction, presence, and performance in an online course. Online Learning, 6(1), 21-40.

Reese, S. A. (2013). Online learning environments in higher education: Connectivism vs. dissociation. International Journal of Instructional Technology and Distance Learning, $10(5), 35-44$.

Richardson, J. C., Koehler, A. A., Besser, E. D., Caskurlu, S., Lim, J., \& Mueller, C. M. (2015). Conceptualizing and investigating instructor presence in online learning environments. The International Review of Research in Open and Distributed Learning, 16(3), 256-297.

Richardson, J. C., \& Lowenthal, P. (2017). Instructor social presence: Learners' needs and a neglected component of the Community of Inquiry framework. In A. L. Whiteside, A. Garrett Dikkers, \& K. Swan (Eds.), Social presence in online learning: Multiple perspectives on practice and research (pp. 86-98). Stylus.

Richardson, J. C., \& Swan, K. (2003). Examining social presence in online courses in relation to students' perceived learning and satisfaction. Journal of Asynchronous Learning Networks, $7(1), 68-88$.

Rogers, C. R. (1961) On becoming a person: A therapist's view of psychotherapy. Houghton Mifflin.

Rogers, C. (1969). Freedom to learn: A view of what education might become (1st ed.). Charles Merrill.

Rogers, C., Lyon, H. C., \& Tausch, R. (2013) On becoming an effective teacher-Personcentered teaching, psychology, philosophy, and dialogues with Carl R. Rogers and Harold Lyon. Routledge.

Shea, P., \& Bidjerano, T. (2009). Community of Inquiry as a theoretical framework to foster "epistemic engagement" and "cognitive presence" in online education. Computers and Education, 52(3), 543-553.

Shea, P., Li, C-S., Swan, K., \& Pickett, A. (2005). Developing learning community in online asynchronous college courses: The role of teaching presence. Journal of Asynchronous Learning Networks, 9(4), 59-82. 
Simmons, J., Roberge, L., Kendrick, S. B. Jr., \& Richards, B. (1995). The interpersonal relationship in clinical practice. The Barrett-Lennard Relationship Inventory as an assessment instrument. Evaluation and the Health Professions, 18(1), 103-112.

Smetko, J. A. (1982/1983). Student perceived facilitation as a correlate of academic achievement, academic self-concept and self-concept among inner city seventh and eighth graders [Doctoral dissertation, Alberta University]. Dissertation Abstracts international, 43, 1902-A. https://archive.org/stream/ERIC_ED358616/ERIC_ED358616_djvu.txt

Smith, M. K. (2004) Carl Rogers and informal education. The Encyclopedia of Pedagogy and Informal Education. www.infed.org/thinkers/et-rogers.htm.

Swan, K., Day, S. L., Bogle, L. R., \& Matthews, D. B. (2014). A collaborative, design-based approach to improving an online program. Internet and Higher Education, 21, 74-81.

Swan, K., \& Shih, L-F. (2005). On the nature and development of social presence in online course discussions. Journal of Asynchronous Learning Networks, 9(3), 115-136.

Tabachnick, B. G., Fidell, L. S., \& Ullman, J. B. (2007). Using multivariate statistics (5th ed.). Pearson.

Tausch, R., \& Hüls, R. (2013). Students, patients, and employees cry out for empathy, In C. R. Rogers., H. C. Lyon, Jr., \& R. Tausch (Eds.), On becoming an effective teacher: Personcentered teaching, psychology, philosophy, and dialogues with Carl R. Rogers. Routledge.

Vaughan, N., \& Garrison, D. R. (2006). How blended learning can support a faculty development community of inquiry. Journal of Asynchronous Learning Networks, 10(4), 139-152.

Zhu, M., Herring, S. C., \& Bonk, C. (2019). Exploring presence in online learning through three forms of computer-mediated discourse analysis. Distance Education, 40(2), 205-225. 